\title{
A Technical Note on the Application of Interpolation Method on Modeling of 3D Surface Rock Layer
}

\author{
Songyu Yin ${ }^{1}$ and Yu Zhou $\mathbb{1 D}^{2}$ \\ ${ }^{1}$ CCCC Tianjin Dredging Co. Ltd., Tianjin Key Laboratory for Dredging Engineering Enterprises, No. 14 Mu Ning Road, \\ Tianjin. 300457, China \\ ${ }^{2}$ Complex Condition Drilling Experiment Center, Jilin University, No. 6 Ximinzhu Street, Changchun. 130012, China
}

Correspondence should be addressed to Yu Zhou; yu.zhou.19921105@gmail.com

Received 11 November 2019; Revised 3 July 2020; Accepted 16 July 2020; Published 3 August 2020

Academic Editor: Valeria Vignali

Copyright (C) 2020 Songyu Yin and Yu Zhou. This is an open access article distributed under the Creative Commons Attribution License, which permits unrestricted use, distribution, and reproduction in any medium, provided the original work is properly cited.

\begin{abstract}
The planning stages of dredging require comprehensive and detailed analyses. Identifying the dredging environment is one of the important points. A three-dimensional (3D) geological modeling technology has been shown to be a robust tool for representing and analyzing the conditions of geology. From a general perspective, a 3D model is established by some spatial surfaces. Based on a dredging project, this study investigated the estimation capability of an interpolation method of triangulation combined with $\mathrm{BP}$ neural network, for modeling a rock layer surface. The performance of the proposed model is compared with some conventional methods in the literature. The results showed that this interpolation method is effective to be employed for surface modeling of the rock layer.
\end{abstract}

\section{Introduction}

A reasonable judgment about the location of all soil types in the dredging area is one of the most important elements for the planning of maritime dredging operations, as the material to be dredged determines the selection of dredging equipment and drives the productivity computations [1-3]. With the advance of science, a 3D geological modeling technology has been shown to be a robust tool for representing and analyzing the conditions of geology $[4,5]$. From a general perspective, a 3D model is established by some spatial surfaces. In other words, if surfaces are determined, the 3D model can be obtained easily among these surfaces.

Surface modeling needs some necessary information, such as real data at sampled sites and predicted values at unsampled sites. Interpolation is the process of predicting the values of attributes at unsampled sites. Many researchers have carried out studies on interpolation methods for the purpose of providing an optimum model structure [6-10]. For an unsampled point in the spatial position, the closer it is to the sampled point, the more likely the attribute value is similar, and this is the most basic assumption of spatial interpolation methods [11]. On this basis, various interpolation methods have been formed for surface estimation, such as triangulation interpolation, inverse distance weighting, nearest neighbor, and splines methods $[12,13]$.

In addition, some scholars try to apply artificial intelligence technology to the study of spatial interpolation methods. Lin and Chen proposed an attribute interpolation method based on radial basis function networks and variograms [14]. Samanta and Bandopadhyay also used radial basis function network for attribute interpolation, and a genetic algorithm was introduced in their study [15]. Tutmez carried out the research of interpolation methods based on fuzzy mathematical algorithms [16]. In the present study, a triangulation interpolation method combined with BP neural network is used for surface modeling. According to the real borehole data information in a dredging project, the availability for rock formation identification based on this interpolation method is examined. Moreover, a 3D model of rock stratum distribution in the construction area is established, and the amount of rock is estimated. 


\section{Methodology}

2.1. Description of Problem. There are three types of $3 \mathrm{D}$ models which are wireframe, surface, and solid models, and these models completely and unambiguously define the stratigraphy for the site being modeled [17]. As it is known, a solid model can be created by extending the top surface down to the bottom surface of geologic units. Surface modeling is crucial as it affects the accuracy of solid modeling. Thus, the utility of different methods over conventional methods should be investigated.

\subsection{Conventional Interpolation Methods}

2.2.1. Triangulation Interpolation. Triangulation interpolation is the most common and simplest interpolation method, especially in geographic information systems. For this method, the equation of a simple planar surface is

$$
Z(x, y)=a_{0}+a_{1} \cdot x+a_{2} \cdot y,
$$

where $Z(x, y)$ is the attribute value at the specified location $(x, y)$ and $a_{0}, a_{1}$, and $a_{2}$ are unknown coefficients that can be found by solving three normal equations of the known coordinates $(Z(x, y), x, y)$ of three points.

The triangular region surrounded by the three points is called the natural neighbors [18]. Except the three points, any sampling points are not allowed to exist in this region. By assuming that the calculated coefficients are constant within the natural neighbors, the attribute value $Z(x, y)$ of any location $(x, y)$ within the region can be estimated.

2.2.2. Inverse Distance Weighting Interpolation. Inverse distance weighting interpolation is a method in which the distance between the interpolation point and the sample point is used as the weight [19]. That means the closer the sample point is to the interpolation point, the greater the weight assigned in the calculation. In this method, a simple planar surface can be expressed as

$$
Z=\frac{\sum_{i=1}^{n}\left(1 /\left(D_{i}\right)^{2}\right) Z_{i}}{\sum_{i=1}^{n}\left(1 /\left(D_{i}\right)^{2}\right)}, \quad(i=1,2,3 \ldots, n),
$$

where $Z$ is the attribute value of the interpolation point, $Z_{i}(i=1,2,3 \ldots, n)$ is the attribute value of the sampling point, $n$ is the number of the sampling points, and $D_{i}$ is the distance between the interpolation point and the $i$ th sampling point.

\subsection{Interpolation Method of Triangulation Combined with BP} Neural Network. A neural network, constructed under the inspiration of biological neural networks, is a data processing model with a large amount of interconnecting artificial neuronst [20]. Researchers perform input data modeling by adjusting the weights and thresholds among neurons, thereby ultimately achieving the capability to solve real problems [21]. The BP neural network is a type of forward neural network, which consists of an input layer, an output layer, and several hidden layers. The weight

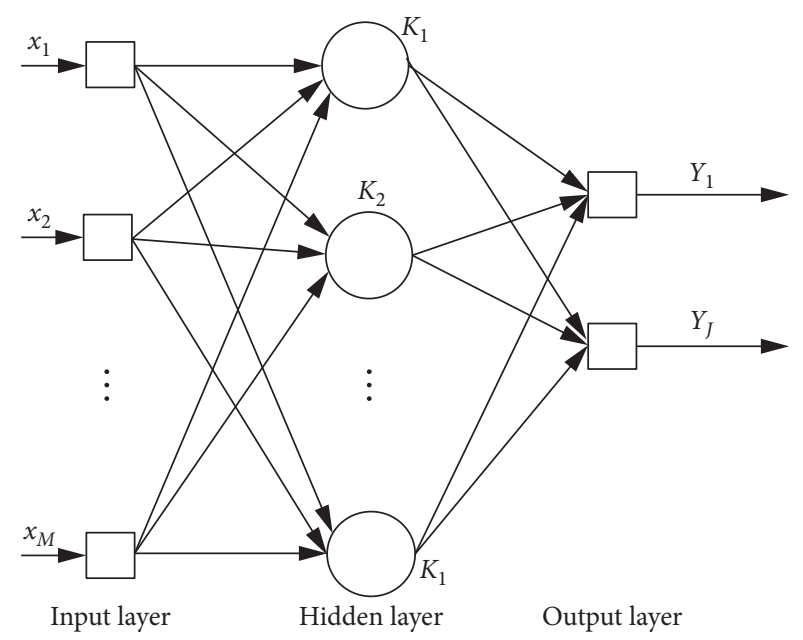

FIgURE 1: Three-layer BP network structure.

coefficient between layers is adjusted by network learning, and only when the coefficient is determined can the correct output value be given according to the input. The BP network learning belongs to the error minimization type of supervised learning, i.e., it requires a learning sample set with known output and minimizes the error between the expected output and actual output through training.

Figure 1 shows a three-layer BP network structure with a vector of length $M$ as the input layer and a vector of length $J$ as the output layer. If $u_{i}$ and $v_{i}$ are used to represent the input and output of the $i$ th layer, respectively, $n$ as the number of iterations, the actual network output is $Y(n)=\left[v_{J}^{1}, v_{J}^{2}, \cdots, v_{J}^{J}\right]$. When the expected network output is $d(n)=\left[d_{1}, d_{2}, \cdots, d_{J}\right]$, the error signal of the $n$th iteration can be defined as $e_{j}(n)=d_{j}(n)-Y_{j}(n)$. Thus, the error energy can be defined as

$$
e(n)=\frac{1}{2} \sum_{j=1}^{J} e_{j}^{2}(n) .
$$

The interpolation method of triangulation combined with BP neural network, which is used for surface modeling in this study, actually contains two interpolation processes. Figure 2 shows the steps of this method. Firstly, the data points obtained by the actual measurement are generated (Figure 2(a)). Secondly, using these points as learning sample set, virtual data points are randomly generated through BP neural network (Figure 2(b)). Finally, based on all data points (measured and virtual), the natural neighbors are determined by triangulation (Figure 2(c)). It can be found that the vertices of each triangle region contain at least one virtual data point.

\section{Case Studies}

3.1. Project Description and Borehole Data Information. The interpolation method of triangulation combined with $\mathrm{BP}$ neural network is applied in the $3 \mathrm{D}$ geological modeling of a dredging area. This area, which has a design excavation depth of $13.5 \mathrm{~m}$, is located at one coast of China, and the 


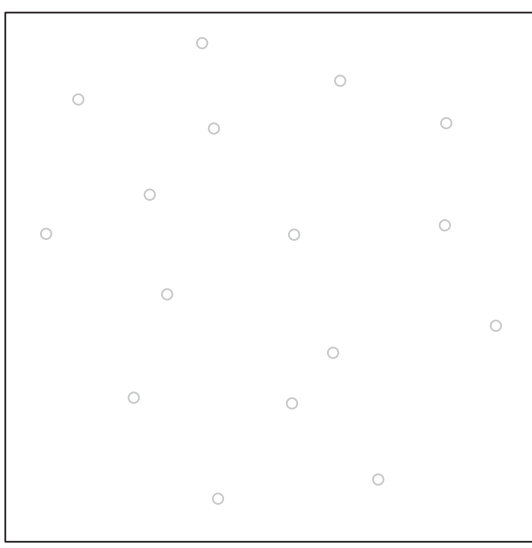

(a)

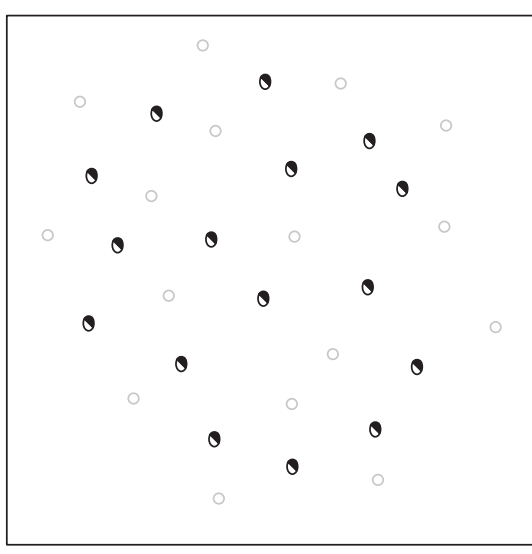

(b)

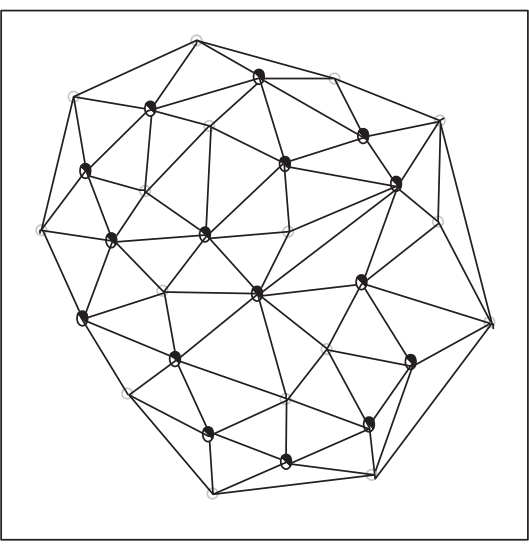

(c)

FIGURE 2: Steps of the interpolation method of triangulation combined with BP neural network: (a) scattered measured data points; (b) random virtual data points; (c) all triangles formed with data points as vertices.

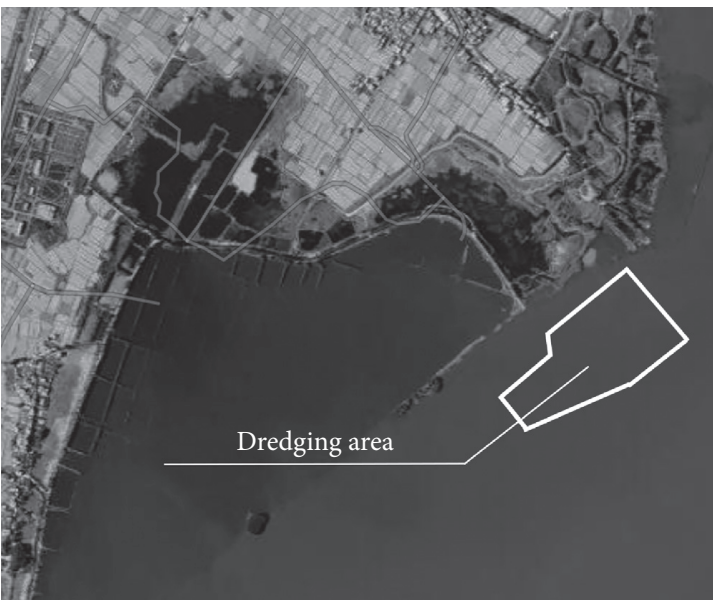

\begin{tabular}{lccc}
\hline \multirow{2}{*}{$\begin{array}{l}\text { Borehole } \\
\text { number }\end{array}$} & \multicolumn{2}{c}{ Location } & $\begin{array}{c}\text { Elevation of boundary between soil } \\
\text { layer and rock layer }(\mathrm{m})\end{array}$ \\
\cline { 2 - 3 } B01 & $X$ & $Y$ & -13.5 \\
B02 & 96.25 & -79.54 & -13.5 \\
B03 & 185.61 & -61.19 & -13.5 \\
B04 & 259.52 & 40.94 & -13.5 \\
B05 & 98.98 & 148.8 & -7.35 \\
B06 & 341.78 & 144.47 & -13.5 \\
B07 & 277.11 & 390.07 & -4.55 \\
B08 & 465.88 & 288.14 & -6.9 \\
B09 & 589.89 & 193.58 & -12.5 \\
B10 & 470.55 & 118.36 & -13.5 \\
B11 & 188.25 & 269.46 & -5.9 \\
B12 & 262.15 & 146.36 & -10.3 \\
\hline
\end{tabular}

FIGURE 3: Project area and borehole information.

main dredged materials are soil and rock. Compared with soil, rock excavation is more difficult and requires higher construction costs. Therefore, the 3D model research mainly focuses on the rock layer, and the amount of excavation is paid special attention. A total of 12 boreholes can be used for model establishment. To make the method more general, a reference point (B01) is determined, and the coordinate of which is defined as $(X, Y)=(0,0)$. Once the reference point is determined, other borehole data can be easily converted. Some important information are listed in Figure 3.

3.2. Network Establishment and Evaluation. The establishment and training of BP neural networks are implemented using computer software. Quasi-Newton algorithm is used for network training, and some relative parameters are shown in Table 1.

Figure 4 shows the distribution of boreholes. It can be seen that 10 of the 12 boreholes are used for network establishment, and the other two are used to test the network. The borehole information should be preprocessed before
TABLe 1: Parameter settings.

\begin{tabular}{lc}
\hline Parameter & Value \\
\hline Maximum number of training & 1000 \\
Count of hidden layers & 8 \\
Learning rate & 0.01 \\
Training requirements accuracy & 0 \\
\hline
\end{tabular}

training. Each borehole is divided into several data points from the bottom up, with an interval of $0.2 \mathrm{~m}$. The output of the data points above the elevation of boundary between the soil layer and rock layer is counted as 0 , and others as 1 . Therefore, the input layer of the BP neural network consists of 3 factors which are the location $(x, y)$ and depth, and the output layer only consists of a signal sequence of 0 and 1 . After preprocessing, there are totally 670 data points for network establishment and 134 data points for the test. Random assignment is made among the data points used for network establishment, which is 70\% for training and $30 \%$ for verification. For a certain 


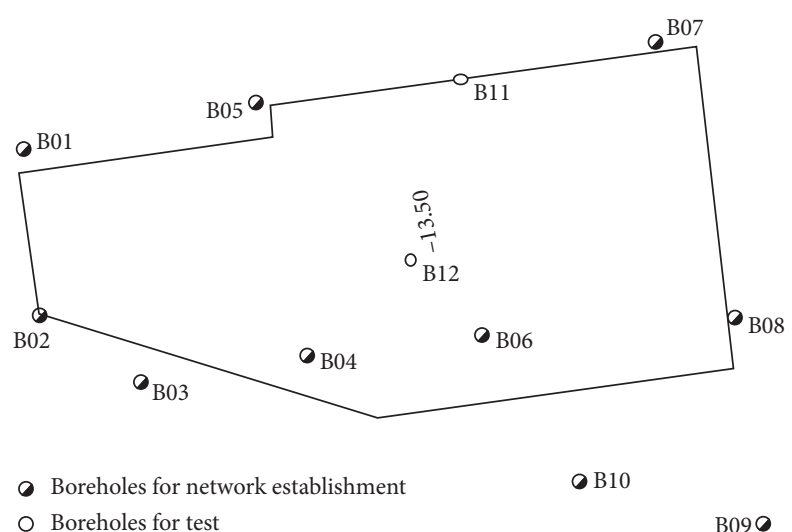

Figure 4: Borehole distribution.

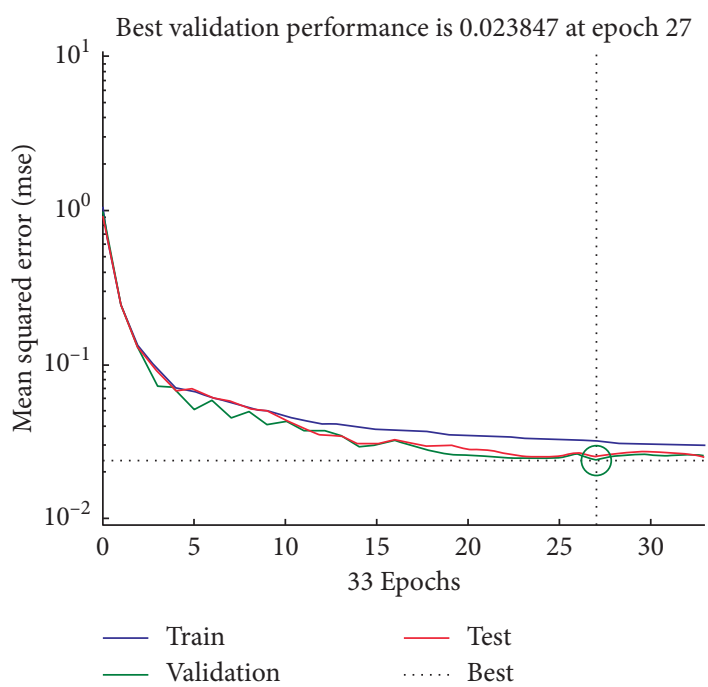

FiguRE 5: Error performance curve.

location, the elevation of boundary $d$ can be obtained by the following equation:

$$
d=0.2 \cdot n+0.1
$$

where $n$ is the number of elements with an output of 1 in the depth direction.

The operation results of BP neural network are shown in Figures 5 and 6. Figure 5 reflects the trend of network error performance under different iterations. It can be concluded that the error of training samples, verification samples, and test samples decreases as the number of iterations increases. The minimum errors of the training sample and the test sample are 0.0298 and 0.0238 , respectively, and the correct rate of the network is $98.5 \%$. Figure 6 is the regression analysis diagram of BP neural network sample data. As can be seen from the figure, the linear correlation coefficients of the training sample, the verification sample, the test sample, and all the samples are $0.897,0.929,0.918$, and 0.906 , respectively. According to the operation results, the trained values of the network roughly match the actual values.
3.3. Comparison of Results. As mentioned above, 2 boreholes are used for testing. Table 2 is a comparison of the 3 interpolation methods described in the present study. For both boreholes, the predicted value obtained with the BP neural network method is much closer to the actual value. Compared with the inverse distance weighting, the means for adjusting the weight by multiple iterations in the BP neural network method seems to be more reasonable than simply using the square of the distance as the weight, especially in dealing with boundary line interpolation. Moreover, all the borehole information provided is utilized in the BP neural network method, which is different from the triangulation interpolation.

In addition, the BP neural network also provides a way to estimate the maximum error of the elevation of boundary between the soil layer and rock layer. If $\eta, m$, and $k$ represent the correct rate of the network, the sampling interval, and the count of sample points, respectively, the maximum error can be expressed as follows:

$$
E=[\eta \cdot k+0.5] \cdot m .
$$



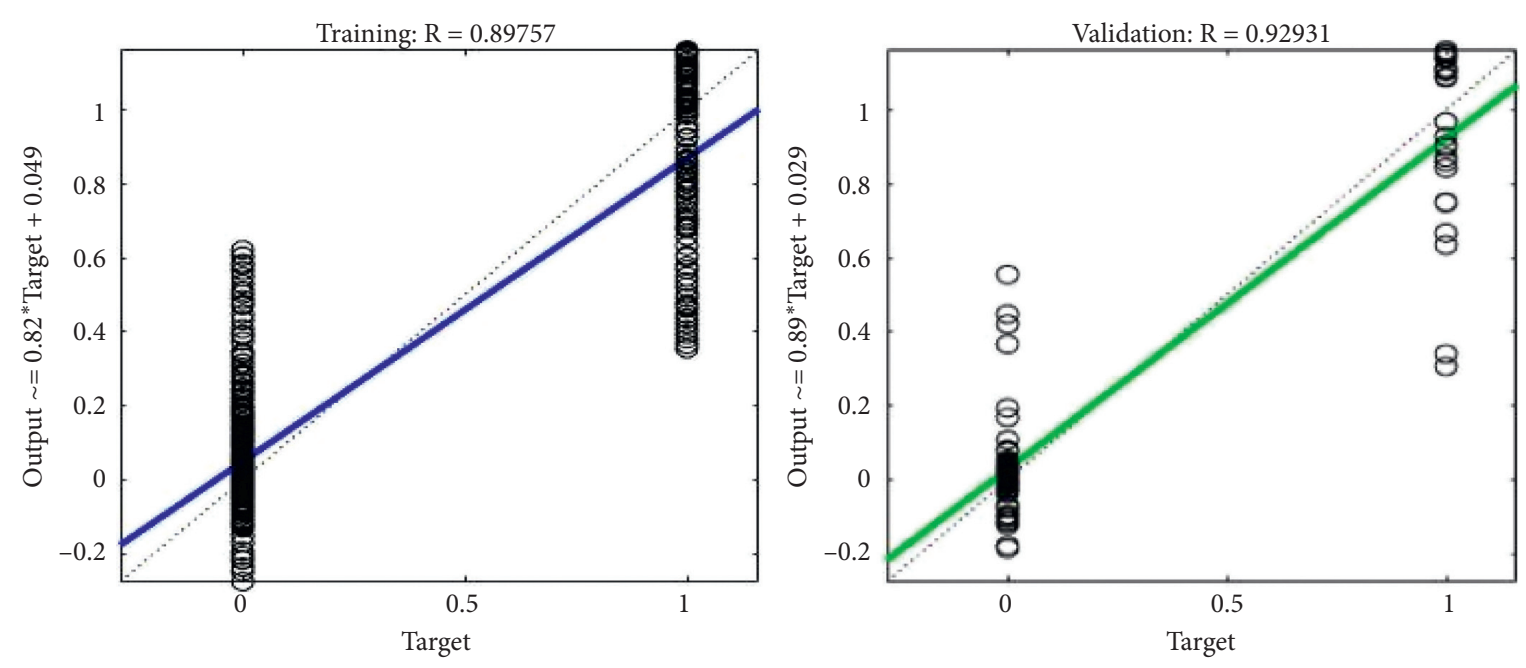

$$
\begin{array}{ll}
0 \quad \text { Data } \\
\text { Fit } \\
\cdots \cdots & Y=T
\end{array}
$$

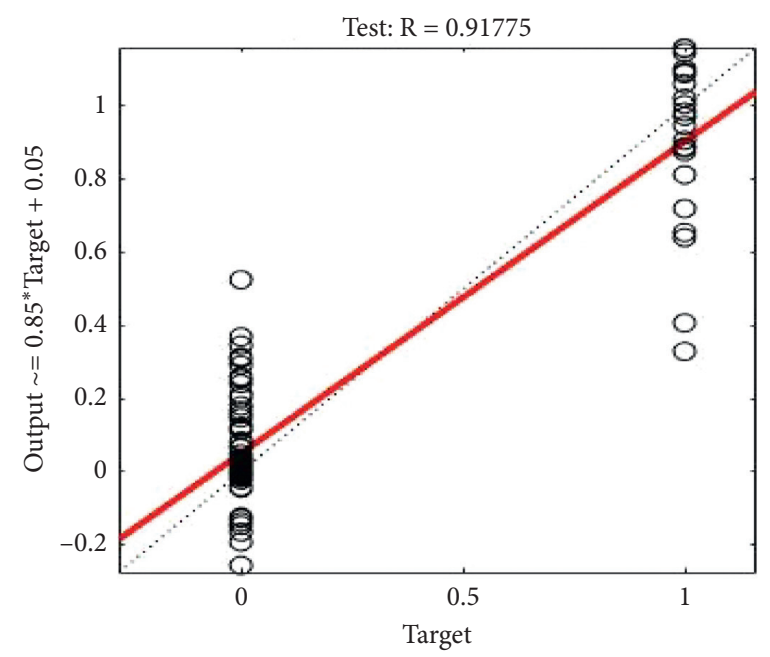

O Data

- Fit

$$
Y=T
$$

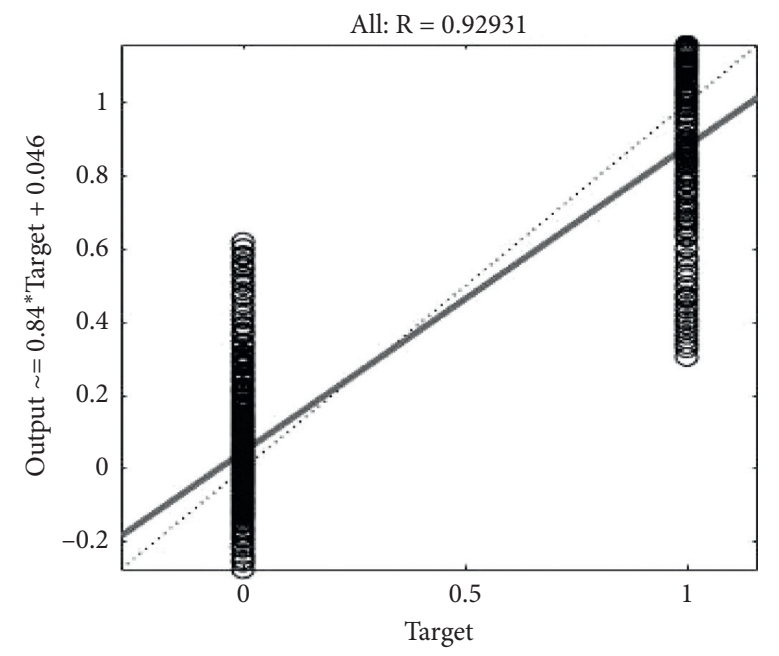

$$
\begin{array}{ll}
\text { O Data } \\
- \text { Fit }
\end{array}
$$

\begin{tabular}{|c|c|c|c|c|c|c|}
\hline \multirow[t]{2}{*}{ Borehole number } & \multicolumn{2}{|c|}{ Location } & \multirow[t]{2}{*}{ Interpolation method } & \multirow[t]{2}{*}{ Number of borehole for calculation } & \multicolumn{2}{|c|}{$\begin{array}{c}\text { Elevation of } \\
\text { boundary between } \\
\text { soil layer and rock } \\
\text { layer }(\mathrm{m})\end{array}$} \\
\hline & $X$ & $Y$ & & & Actual & Predicted \\
\hline B11 & 470.55 & 118.36 & $\begin{array}{c}\text { Triangulation } \\
\text { Inverse distance weighting } \\
\text { BP neural network } \\
\text { Triangulation }\end{array}$ & $\begin{array}{l}\text { B05, B07, B08 } \\
\text { All } \\
\text { All } \\
\text { B05, B06, B11 }\end{array}$ & -5.9 & $\begin{array}{l}-5.97 \\
-12.28 \\
-5.9 \\
-11.47\end{array}$ \\
\hline B12 & 262.15 & 146.36 & $\begin{array}{c}\text { Inverse distance weighting } \\
\text { BP neural network }\end{array}$ & $\begin{array}{l}\text { All } \\
\text { All }\end{array}$ & -10.3 & $\begin{array}{l}-11.23 \\
-10.3\end{array}$ \\
\hline
\end{tabular}$$
\text { O Data }
$$$$
\text { Fit }
$$$$
\text { …. } Y=T
$$

Figure 6: Regression analysis chart of sample data.

TABLE 2: Comparison of the 3 interpolation methods. 


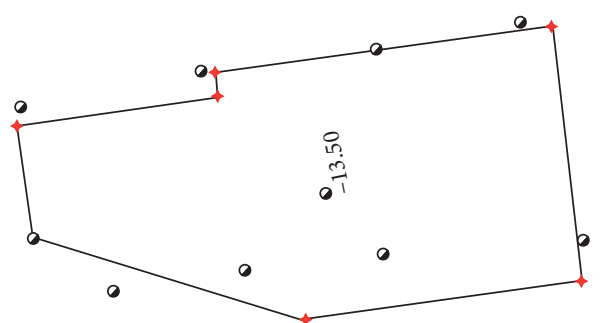

(a)

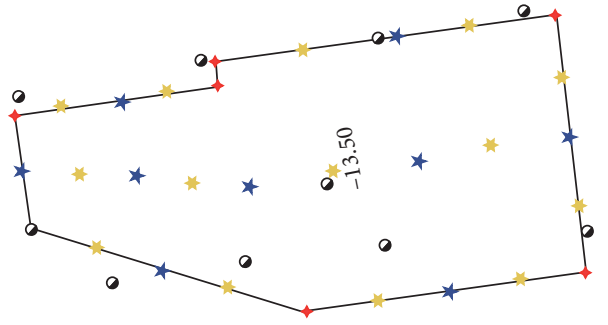

(c)

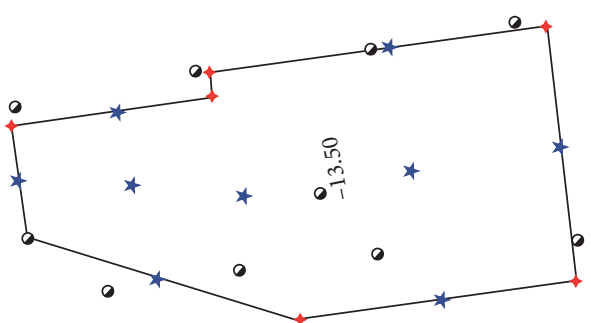

(b)

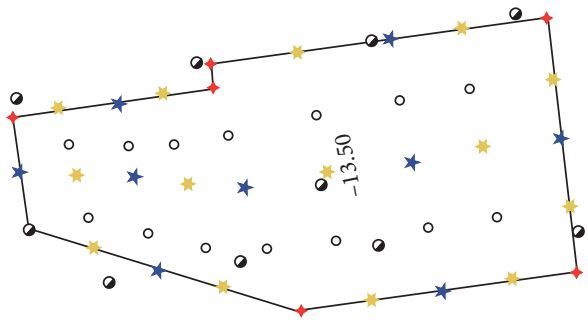

(d)

Figure 7: Steps of virtual drilling arrangement. (a) Step 1. (b) Step 2. (c) Step 3. (d) Step 4.

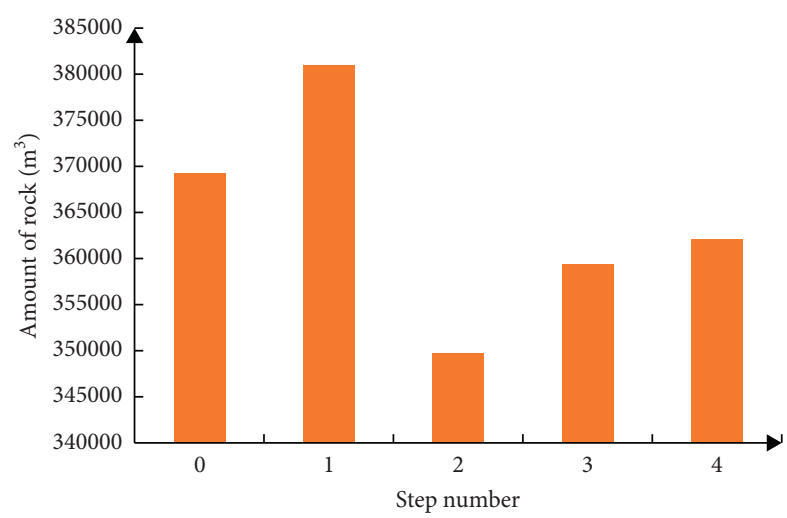

Figure 8: Amount of rocks in each step.

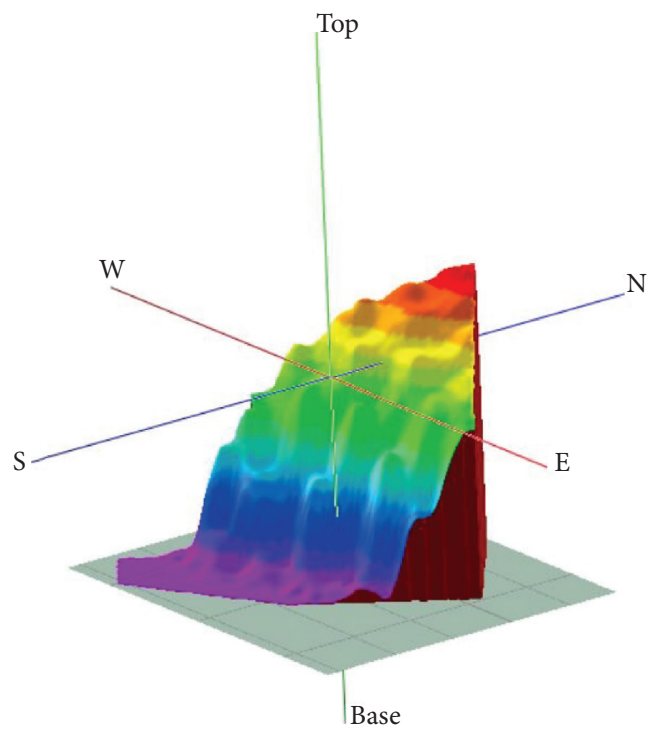

(a)

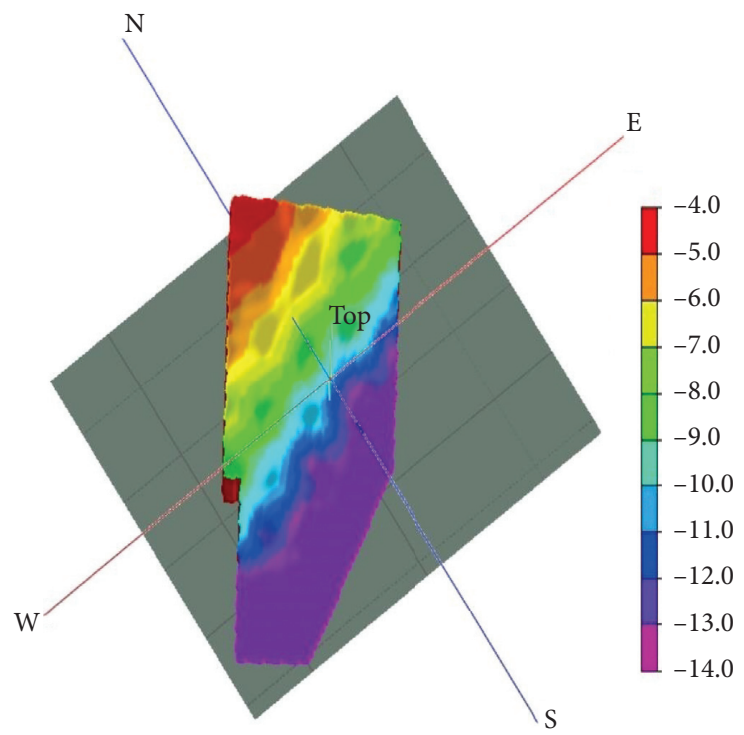

(b)

Figure 9: 3D model of the dredging area: (a) front view; (b) vertical view. 
In this study, $\eta$ is $98.5 \%, m$ is $0.2 \mathrm{~m}$, and $k$ is 67 , so that the maximum error $E$ is $0.2 \mathrm{~m}$.

3.4. 3D Modeling. In the modeling based on triangulation interpolation, the number and distribution of boreholes have a great impact on the partitioning of natural neighbors. Therefore, it can be inferred that the virtual drilling arrangement is an important part in the modeling using the interpolation method of triangulation combined with BP neural network. 4 steps of virtual drilling arrangements are made in this paper, aiming at obtaining a more accurate $3 \mathrm{D}$ model. Figure 7 shows these steps. As can be seen, the first step mainly focuses at the arrangement of key nodes on the boundary lines, while the other steps are the uniform arrangement of the entire dredging area.

Figure 8 shows the amount of rocks at each stage, calculated by the model. It can be seen that as the drilling arrangement is refined, the change of rock amount gradually reduced. When step 4 of virtual drilling arrangement is completed, the change of rock amount is less than $5,000 \mathrm{~m}^{3}$, compared to step 3. This result has reached the owner's request, and the final statistic of rock is $362,131 \mathrm{~m}^{3}$.

After completing the arrangement of virtual drilling, the 3D model can be established, as shown in Figure 9. It can be seen from the figure that the distribution of the rock layer is between -4 and -13.5 in depth, the trend is gradually increasing from west to east, and the highest part is located in the upper right corner of the dredging area. This model provides strong support for the dredging operation planning of the project.

\section{Conclusions}

Sensitively generated surface models have a crucial importance for the optimum planning and $3 \mathrm{D}$ modeling. In this study, a new interpolation method is used for modeling a surface of the rock layer. Based on a dredging project, the result is compared with 2 conventional interpolation methods.

As a result, some merits of the interpolation method of triangulation combined with BP neural network have been recorded. First, this method has provided more accurate results. Second, it gives a way to calculate the maximum error of interpolation points, and the training accuracy rate of BP neural network is considered to be closely related to the error.

Finally, the 3D model of the dredging area is established using this new interpolation method, and the statistic of rock is determined. This case of application aims to provide a new example for material reserve estimation.

\section{Data Availability}

The data used to support the findings of this study are available from the corresponding author upon request.

\section{Disclosure}

The BP neural network calculation has been done by using the MATLAB2016a software, The relative code is wrote by the corresponding author of this paper, and the name of code is sci-code. The repository link is https://share.weiyun. com/DP6mGX5q.

\section{Conflicts of Interest}

The authors declare that they have no conflicts of interest.

\section{References}

[1] M. J. Anderson and B. D. Barkdoll, "Incorporation of air emissions in dredging method selection," Journal of Waterway, Port, Coastal, and Ocean Engineering, vol. 136, no. 4, pp. 191-199, 2010.

[2] C. A. Blazquez, T. M. Adams, and P. Keillor, "Optimization of mechanical dredging operations for sediment remediation," Journal of Waterway, Port, Coastal, and Ocean Engineering, vol. 127, no. 6, pp. 299-307, 2001.

[3] N. Manap and N. Voulvoulis, "Risk-based decision-making framework for the selection of sediment dredging option," Science of The Total Environment, vol. 496, pp. 607-623, 2014.

[4] A. M. Lemon and N. L. Jones, "Building solid models from boreholes and user-defined cross-sections," Computers \& Geosciences, vol. 29, no. 5, pp. 547-555, 2003.

[5] L. Zhu, C. Zhang, M. Li, X. Pan, and J. Sun, "Building 3D solid models of sedimentary stratigraphic systems from borehole data: an automatic method and case studies," Engineering Geology, vol. 127, pp. 1-13, 2012.

[6] H. Apaydin, F. Sonmez, and Y. Yildirim, "Spatial interpolation techniques for climate data in the GAP region in Turkey," Climate Research, vol. 28, pp. 31-40, 2004.

[7] P. Calcagno, J. P. Chiles, G. Courrioux, and A. Guillen, "Geological modelling from field data and geological knowledge Part I. Modelling method coupling 3D potentialfield interpolation and geological rules," Physics of the Earth and Planetary Interiors, vol. 171, pp. 14-157, 2008.

[8] A. Dag and B. A. Mert, "Evaluating thickness of bauxite deposit using indicator geostatistics and fuzzy estimation," Resource Geology, vol. 58, no. 2, pp. 188-195, 2008.

[9] C. A. Schloeder, N. E. Zimmerman, and M. J. Jacobs, "Comparison of methods for interpolating soil properties using limited data," Soil Science Society of America Journal, vol. 65 , no. 2, pp. 470-479, 2001.

[10] Y. Xie, T.-b. Chen, M. Lei et al., "Spatial distribution of soil heavy metal pollution estimated by different interpolation methods: accuracy and uncertainty analysis," Chemosphere, vol. 82, no. 3, pp. 468-476, 2011.

[11] M. Hajiazizi and M. R. Ashory, "Application of point interpolation method in jointed rock mass," International Journal of Computational Methods, vol. 8, no. 1, pp. 41-55, 2011.

[12] O. Falivene, L. Cabrera, R. Tolosana-Delgado, and A. Sáez, "Interpolation algorithm ranking using cross-validation and the role of smoothing effect. A coal zone example," Computers \& Geosciences, vol. 36, no. 4, pp. 512-519, 2010.

[13] B. K. Nayak, S. K. Sahu, and R. K. Sahoo, "Trend surface modelling of karlapat bauxite deposit, eastern ghat group, Orissa, India," Resource Geology, vol. 52, no. 3, pp. 239-248, 2002.

[14] G. F. Lin and L. H. Chen, "A spatial interpolation method based on radial basis function networks incorporating a semivariogram model," Journal of Hydrology, vol. 288, no. 3-4, pp. 288-298, 2004. 
[15] B. Samanta and S. Bandopadhyay, "Construction of a radial basis function network using an evolutionary algorithm for grade estimation in a placer gold deposit," Computers \& Geosciences, vol. 35, no. 8, pp. 1592-1602, 2009.

[16] B. Tutmez, "An uncertainty oriented fuzzy methodology for grade estimation," Computers \& Geosciences, vol. 33, no. 2, pp. 280-288, 2007.

[17] D. Ahmet and C. O. Ali, "A comparative study for 3D surface modeling of coal deposit by spatial interpolation approaches," Resource Geology, vol. 63, no. 4, pp. 394-403, 2013.

[18] A. I. Ben, M. Jribi, F. Ghorbel, M. Mars, and T. Kraiem, "Quantitative evaluation of fiber tractography with a Delaunay triangulation-based interpolation approach," Medical \& Biological Engineering \& Computing, vol. 57, no. 4, pp. 925-938, 2019.

[19] B. M. Urszula, M. Jacek, O. Radomir, and P. Wojciech, "A comparison of some interpolation techniques for determining spatial distribution of nitrogen compounds in groundwater," International Journal of Environmental Research, vol. 13, no. 4, pp. 679-687, 2019.

[20] C. Li and C. Yu, "Performance evaluation of public non-profit hospitals using a BP artificial neural network: the case of hubei province in China," International Journal of Environmental Research and Public Health, vol. 10, no. 8, pp. 3619-3633, 2013.

[21] Z. Y. Jia, S. L. Zhou, Q. L. Su, H. M. Yi, and J. X. Wang, "Comparison study on the estimation of the spatial distribution of regional soil metal(loid)s pollution based on kriging interpolation and BP neural network," International Journal of Environmental Research and Public Health, vol. 15, no. 34, pp. 1-14, 2017. 